\title{
Synthesis of Nanowires by Spray Pyrolysis
}

\author{
Kalyana C. Pingali, Shuguang Deng, and David A. Rockstraw \\ Department of Chemical Engineering, New Mexico State University, P.O. Box 30001, MSC 3805, Las Cruces, NM 88003, USA \\ Correspondence should be addressed to Shuguang Deng, sdeng@nmsu.edu
}

Received 9 October 2008; Revised 3 January 2009; Accepted 25 March 2009

Recommended by Joan Ramon Morante

\begin{abstract}
Nanowires of carbon as well as nickel-carbon (Ni-C) were synthesized by spray-pyrolysis. The carbon nanowires were synthesized using methanol as a precursor while the $\mathrm{Ni}-\mathrm{C}$ nanowires were obtained by using nickel chloride methanol solution as feed. It was found that low argon carrier gas flow rates $\left(<100 \mathrm{~cm}^{3} / \mathrm{min}\right)$ and suitable reaction temperatures $\left(\sim 700^{\circ} \mathrm{C}\right)$ were found to be critical for the formation of wired structures. The formation of nanowires was quite sensitive to reaction temperature. Nanowires could not form at temperatures higher than $900^{\circ} \mathrm{C}$ in the presence of hexane. Ruthenium chloride and nickel chloride dissolved in hexane and methanol resulted in carbon coated binary metallic nanoparticles. Morphological differences of carbon nanowires, Ni-C wires and carbon coated binary nanoparticles were characterized by scanning electron microscopy (SEM) and energy-dispersive X-ray analysis (EDS). The formation mechanism for the wired structures is proposed to explain the structural results obtained.
\end{abstract}

Copyright (C) 2009 Kalyana C. Pingali et al. This is an open access article distributed under the Creative Commons Attribution License, which permits unrestricted use, distribution, and reproduction in any medium, provided the original work is properly cited.

\section{Introduction}

In recent years, particle morphology has been a point of interest for investigative and scientific purposes in the field of nanotechnology. Several methods have been used to synthesize nanotubes and nanowires of carbon. Among them, the synthesis route involving the evaporation of aerosols is of interest due to a simplified processing technique for the synthesis of carbon nanotubes. Research into the synthesis of nanotubes is growing due to a strong interest in the application of nanotube junctions in the field of electronics [1]. A variety of processes have been disclosed for the synthesis of carbon nanotubes. Biró et al. [2] synthesized single-walled and multiwalled carbon nanotubes by spray-pyrolysis. Spray-pyrolysis is considered to be an improved catalyzed chemical vapor deposition technique for the production of nanotubes [3]. Nanotubes synthesized by spray-pyrolysis are found to have some unique properties when they are compared to nanotubes prepared by the conventional methods [4]. A method found to produce nanotubes of uniform diameter would be of technological importance. The study by Vivekchand et al. [5] using organometallics such as ferrocene in a hydrocarbon solvent generated nanotubes of uniform diameter. Therefore, the nature of the synthesis process is vital to the morphology and directional growth of the produced nanotubes. It was found that the growth direction of nanotube during the synthesis process can determine its alignment [6]. An interesting study showed that an amorphous carbon was obtained when an alcohol solvent was used as the carbon source [7]. A catalyst containing a source of iron will catalyze the decomposition of carbon nanotubes forming amorphous carbon particles [7].

Although several synthesis processes of nanotubes have been studied, their importance in potential sensor applications continues to fascinate many scientists. Nanowires synthesized from electrodeposition technique were found to be used as potential devices for nanomagnetic sensors [8]. Vertically aligned nanowires arrays were found to substantially improve the sensitivity of the sensors [9]. Therefore, in addition to the synthesis process, nanoarrays and nanostructures were found to play a significant role in sensing technology. Nanowires were found to have significant importance not only in electronic sensors but also in gas sensors and biosensors. Nanotube or nanowire structures of tinoxide were used in gas sensor applications [10]. Synthesis of nanowires were found to have potential applications in transistors, solar cells, and sensors [11, 12]. In addition, detection strategies based on nanowires provided a 

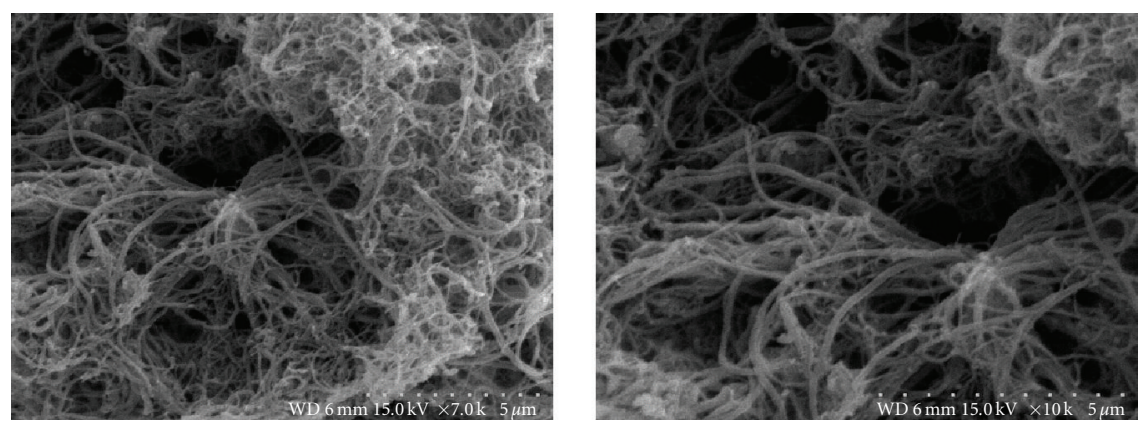

Figure 1: Nanowires of Ni-C. Nickel chloride was dissolved in methanol solution and subjected to spray-pyrolysis through an atomizer at $6 \mathrm{~W}$ and an operating temperature of $700^{\circ} \mathrm{C}$. The tubular formation of structures was temperature sensitive.

promising technology for biosensors in health care industry $[13,14]$. Tin oxide used as gas sensors [15], ultra sensitive sensor technology based on silicon nanowires [16] and the application of GaN nanowires in ultraviolet sensors [17] reveal the importance of nanowires in potential sensor applications. However, product structures formed depends on both the process employed as well as the operating conditions [18].

Although spray-pyrolysis has been employed to synthesize carbon nanotubes and study the dynamic behavior of such structures $[19,20]$, nanowires and nanotube synthesis by a single step process was given little attention in literature. It is logical to believe that the rapid evaporation of the solvent from an aerosol in the spray-pyrolysis method would produce spherical nanoparticles. In this study, the synthesis of nanowires using a single step spray-pyrolysis method without the addition of any iron catalyst is presented.

\section{Experimental}

Spray-pyrolysis process equipment consists of a reactor tube, a furnace, and an ultrasonic atomizer. A detailed experimental setup and operation were discussed previously [21]. The reaction is carried out by subjecting the precursor solution to temperatures at which pyrolysis of the solute will occur. Organic precursors, such as methanol and hexane, were used as feedstocks for the generation of carbon nanowires. The pyrolysis samples obtained were characterized by SEM and EDS. Liquid feed stocks were gravity fed to the atomizer. Nebulization of the thin column of liquid entering the atomizer is facilitated by imparting an ultrasonic frequency to the atomizer. Frequency is controlled by application of an external power supply to the atomizer, which was varied from $5 \mathrm{~W}$ to $10 \mathrm{~W}$. Earlier study from this lab demonstrated that particle size varies with atomizer frequency [22]. The focus of this paper was to produce carbon nanowires from carbon precursor solutions by flash pyrolysis. The argon gas flow rate was maintained low $\left(<100 \mathrm{~cm}^{3} / \mathrm{min}\right)$ to achieve longer residence time. The ranges of operating parameters resulting in tubular structures were determined for making nanowires from aerosol droplets generated from the ultrasonic atomizer nozzle.

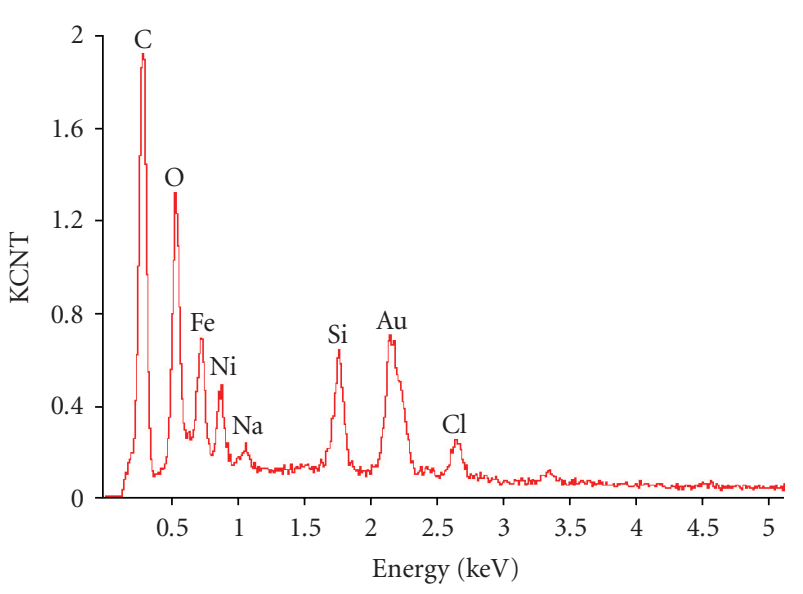

FIGURE 2: EDS spectra of the Ni-C nanowires and nanotubes. Though none of the constituents in the solutions have iron, the presence of Fe in the peak may have been obtained from the walls of the reactor tube. The peak also shows the presence of oxygen which may indicate the formation of oxides.

The reactor tube was preheated under an argon blanket. A vacuum pump was used downstream to sweep during operation. Inlet pressure was fixed at 0.5 bar by adjusting carrier gas flow rate. The top section of the reactor assembly was preheated to $100^{\circ} \mathrm{C}$ to avoid spraying the liquid feed solution upon exiting from the atomizer. Care taken to assure air bubbles did not enter the atomizer feed tube. The flow rate of the feed solution was adjusted using the control knob of the burette in which it was contained. Samples were collected on a quartz substrate and were analyzed by microscopy methods.

\section{Results and Discussion}

Nanowires were obtained by the spray-pyrolysis of nickel chloride dissolved in methanol. Figure 1 shows that nanoparticles are entangled in a web of nanowires of considerable thickness. It is interesting to note that nanowires are not the only constituents of the sample substrate as many spherical particles are also observed tangled in the network of tubes. EDS analysis was employed to study the microstructural 

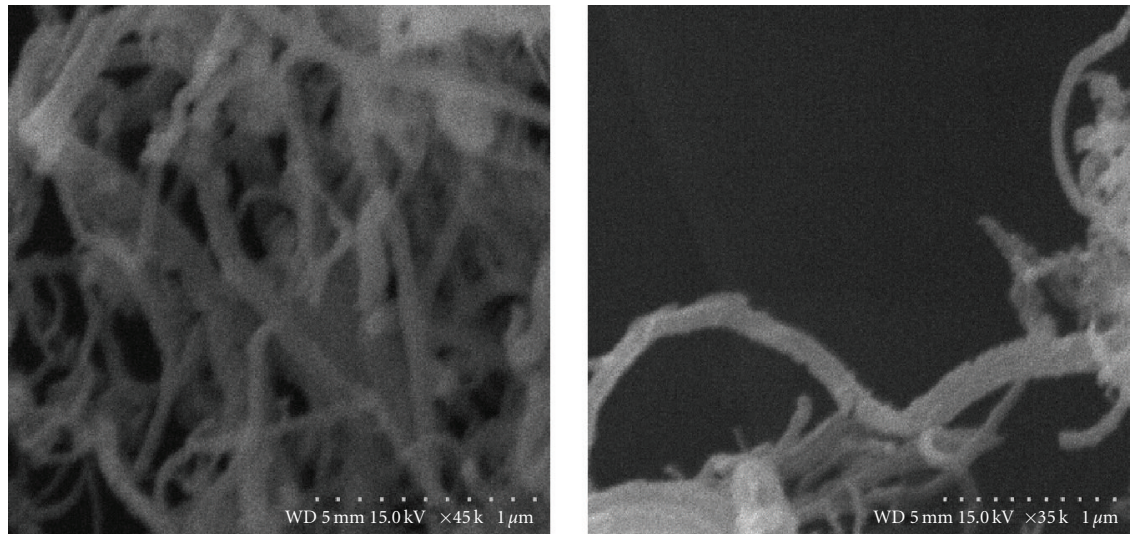

Figure 3: Nanotubes of carbon synthesized from methanol. Precursor fed to atomizer at $6 \mathrm{~W}$ consisted of only methanol. Operating temperature was maintained at $700^{\circ} \mathrm{C}$.

characteristics of the nanowires. A sample consisting of a structure dense with nanowires was generated. It is possible to identify the nanowire formation mechanism using the SEM images.

The exact reason for the formation of nanowires is not known, but it is hypothesized that the catalytic activity of the silica atoms may increase when the particles deposit on the silica substrate. Figure 1 shows the formation of nanowires, tubular structures of unknown crosses sectional area. The low flow rate of feed solution may have contributed to the ability of the system to initiate the growth of a nanowire at the base of the silica substrate. Repetition of the experiment resulted in a similar growth pattern of the deposits, demonstrating that conditions are suitable for nanowire growth. The sample was analyzed for the presence of carbon atoms using EDS. The carbon peak on the EDS spectra in Figure 2 confirms the presence of carbon in the deposits. The corresponding SEM image of the sample analyzed by EDS shown in Figure 2 is given in Figure 3. The SEM images shown in Figure 3 suggest that the carbon nanowires were packed in bundles without ordered alignment, and have a moderately uniform distribution of tube diameters. In these images, one would find a particle (roughly spherical) at the "root" of the tubular structure. This suggests that carbon wire might have grown on top of a nickel nanoparticle that could have catalyzed the tubular carbon growth.

In this study experiments were also performed using both methanol and hexane as the carbon source. It was expected that hexane would result in an increased production of soot as demonstrated in previous studies on amorphous carbon production from pyrolysis process [22]. Figure 4 shows the carbon-coated metallic particles of $\mathrm{Ru}-\mathrm{Ni}$ generated in this work. It is seen that the carbon was amorphous and coated the metallic particle surface in layers.

It can be seen from the Figure 4 that the particles were free of agglomeration may be due to the carbon coating on the surfaces. An excess of carbon was expected in this work due to the presence of excess methanol in the feed solution. As the carbon content of the feedstock

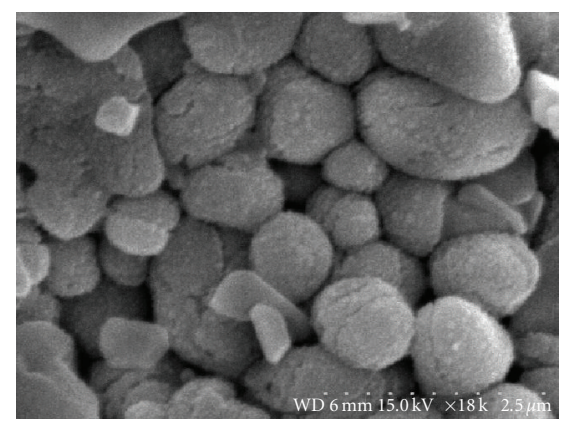

FIGURE 4: Carbon coating on the surface of binary nanoparticles of Ru-Ni. Feed solution consists of ruthenium and nickel chloride dissolved in methanol and hexane. Excess solvent was used which increased the surface coating of carbon. The temperature and atomizer power were maintained at $700^{\circ} \mathrm{C}$ and $6 \mathrm{~W}$. Solute concentration of $10^{-5} \mathrm{M}$ in methanol and hexane was used to facilitate higher fraction of solvent.

increases, the formation of amorphous carbon may increase, particularly as surface coating on surrounding particles [4]. The hypothesis was proposed that metal precursor solutions mixed with a source of excess carbon, would generate metal deposits with an amorphous carbon coating. The catalytic activity of the metal atoms helps CNTs to grow longer [6]. We propose that the amorphous coating of carbon can be due to the use of an organic precursor. Figure 4 shows the particles were not of uniform geometry.

It is interesting to note that the use of methanol has resulted in carbon-coated nanoparticles. Graphitized carbon nanofibers can be produced form alcohol [23]. It was observed here that excess methanol in the precursor solution resulted in a complete coating of the nanoparticles. It must be emphasized that a coating of amorphous carbon was observed when methanol was used as a solvent. This morphology was not observed when only hexane was used in the feed solution. Hexane created individual carbon particles that formed a carbon nanolayer. The metallic particles were subsequently deposited on top of the carbon nanolayer. 


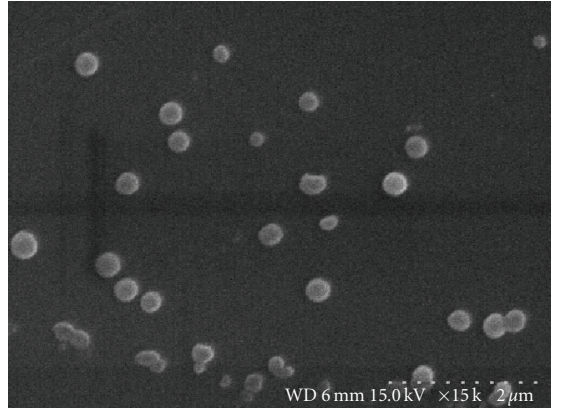

FIGURE 5: Carbon coating on the surface of nanoparticles. Nickel chloride was dissolved in hexane and the feed solution was subjected to an atomizing power of $8 \mathrm{~W}$ with an operating temperature of $900^{\circ} \mathrm{C}$. Individual particles were formed at higher temperature and atomizing power.

Our previous study [24] showed that crystalline cubes were formed when methanol was used as a precursor in a spray pyrolysis chamber at an operating temperature of $750^{\circ} \mathrm{C}$ and an atomizing power of $5 \mathrm{~W}$. Several particle morphologies including spherical, cubic, and dendritic were formed by spray pyrolysis with a varying concentration of methanol in the precursor solution. In addition, our previous study [24] showed that the dendrites were formed with water methanol solution at high temperatures. Interestingly, the particle morphology was found to be dependent upon operating temperature and variation of concentration of solvent in the precursor solution.

In this study, it is believed that thermal disintegration of hexane results in the carbon particles. However, it was interesting to see the deposition of particles when the temperature was increased to $900^{\circ} \mathrm{C}$. It was believed that temperature affects the synthesis of amorphous layers of carbon, with lower operating temperatures producing graphitized carbon particles [23]. As seen from Figure 5, when nickel chloride was dissolved in hexane and processed at high temperature $\left(900^{\circ} \mathrm{C}\right)$, the nanoparticles obtained were free of agglomeration. Figure 5 shows that a uniform dispersion of particles was obtained, deposited on a silicon substrate.

Spectral analysis of the samples in Figure 6 shows the carbon peak, indicating the presence of carbon on the surface of the metallic Ru-Ni particles. The oxygen peak is likely the result of oxidation during sample analysis; while the silica peak is observed due to use of a silicon substrate. During this experiment, the argon carrier gas flow rate was maintained below $100 \mathrm{~cm}^{3} / \mathrm{min}$. This could have resulted in insufficient particle cooling rates. Faster cooling rate can result in rapid precipitation, resulting in disorder in the carbon overlaying [25]. In this study, the low gas flow rate increased residence time. Evaporation rate of the aerosol is not uniform under these conditions, which may have resulted in the peculiar geometry.

The two factors believed to aid the synthesis of nanowires by spray-pyrolysis are: (i) low temperature of $700^{\circ} \mathrm{C}$; (ii) the presence of alcohol in the methanol solution. These

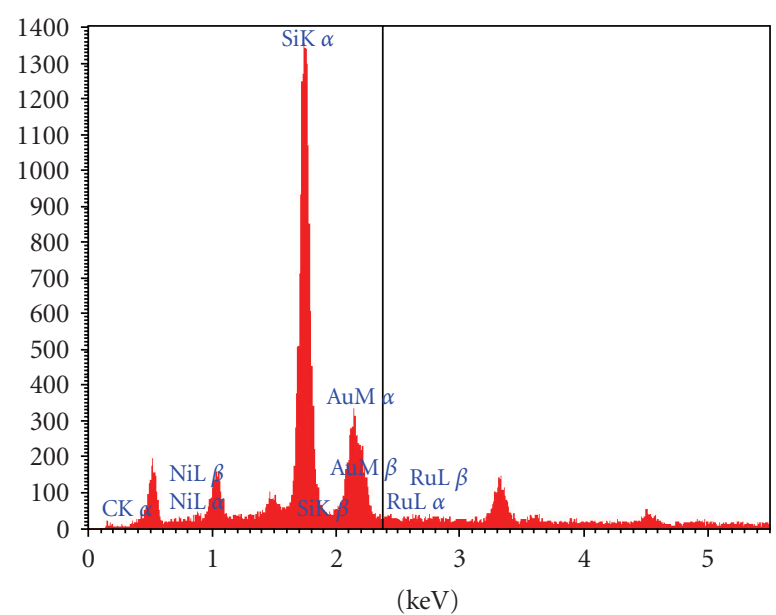

FIGURE 6: EDS spectra of carbon coated binary nanoparticle of Ru$\mathrm{Ni}$. The gold peak in the spectra is present because of the gold coating of the sample before analysis. The substrate was made of silica, and hence the presence of silica peaks.

conditions were employed to synthesize the particles in Figure 7. Slightly lower temperatures of operation can also lead to nanowire formation, but this can happen under the influence of any metal catalyst. It is known that the presence of oxides can enhance the growth of nanotubes. Nickel and iron form oxides which can enhance tubular growth. Formation of nanocarbons as catalysts was promoted by the presence of $\mathrm{NiO}$ and $\mathrm{FeO}$ [23]. Therefore, oxides acted as transition metal oxides catalyzing the nanowire growth process in this study.

Contact with the metallic reactor walls may have catalyzed the growth of nanowires (supported by the presence of iron observed in the EDS spectra). An incomplete inert blanketing in the reactor tube combined with impurities on the wall surfaces might have triggered the formation of metal oxides of nickel and iron that may have catalyzed the growth of nanowires. It is seen in Figure 7 that every nanowire has a particle at the base. It may be that each nanowire originated from a separate particle catalyst particle. The wire structures were observed in clusters. The necessary equipment to quantify tubular morphology was unavailable.

Methanol was dissolved in the precursor solution for carbon coating because it was expected that solubility may determine the amount of coating on the nanoparticle. Solubility of carbon may govern the surface carbon upon precipitation [25]. It was proposed that the solubility of methanol may affect the amount of carbon deposited on the metallic nanoparticles, but this study lacked the analytical support to identify the carbon content on nanoparticle deposits. Consideration of process conditions supports the argument that residence time played a vital role in the geometry of deposits (lower throughput rate may lead to increased wall contact). The continued study to identify the difference in the hollow tubes and wires is of importance in understanding the geometry of nanodeposits. Spraypyrolysis may represent a single step synthesis technique of Ni-C nanostructures. 

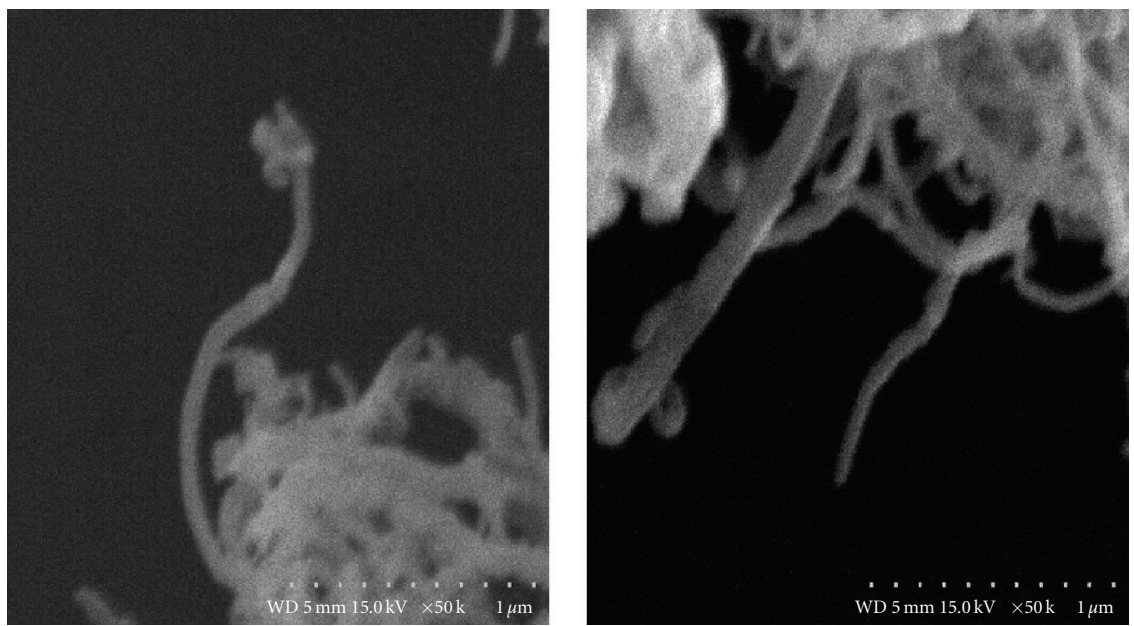

FIgURE 7: Nanotubes of carbon with particle at the base. Nickel chloride in methanol solution was used as a feed solution. The temperature of operation was kept at $700^{\circ} \mathrm{C}$, and atomizer power was maintained at $6 \mathrm{~W}$ throughout the experiment.

\section{Conclusions}

Nanowires can be synthesized by nebulized spray-pyrolysis in a single step process. Low carrier gas flow rate, presence of methanol in the feedstock, particle deposition time, and reactor temperature affect the growth of nanowires. Nanowires were not formed at high temperatures. Methanol and hexane dissolved in the feed solution generate carbon coated nanoparticles. Carbon nanowires can be made from methanol at lower temperature and atomizing power. Amorphous carbon coating is obtained in the presence of an organic precursor. The temperature of operation and the gas flow rate impact the quality of the deposits.

\section{Acknowledgments}

LaSys Inc. is acknowledged for providing the spray-pyrolysis reactor system. Financial support for this project was provided by Space Alliance Technology Outreach Program (SATOP). Initial work on the reactor system was done by Dr. T. J. Mountziaris at State University of New York at Buffalo.

\section{References}

[1] C. P. Deck and K. Vecchio, "Growth mechanism of vapor phase CVD-grown multi-walled carbon nanotubes," Carbon, vol. 43, no. 12, pp. 2608-2617, 2005.

[2] L. P. Biró, Z. E. Horváth, A. A. Koós, et al., "Direct synthesis of multi-walled and single-walled carbon nanotubes by spraypyrolysis," Journal of Optoelectronics and Advanced Materials, vol. 5, no. 3, pp. 661-666, 2003.

[3] Al. Darabont, P. Nemes-Incze, K. Kertész, et al., "Synthesis of carbon nanotubes by spray pyrolysis and their investigation by electron microscopy," Journal of Optoelectronics and Advanced Materials, vol. 7, no. 2, pp. 631-636, 2005.

[4] C. N. R. Rao, A. Govindaraj, G. Gundiah, and S. R. C. Vivekchand, "Nanotubes and nanowires," Chemical Engineering Science, vol. 59, no. 22-23, pp. 4665-4671, 2004.
[5] S. R. C. Vivekchand, L. M. Cele, F. L. Deepak, A. R. Raju, and A. Govindaraj, "Carbon nanotubes by nebulized spray pyrolysis," Chemical Physics Letters, vol. 386, no. 4-6, pp. 313318,2004

[6] R. A. Afre, T. Soga, T. Jimbo, M. Kumar, Y. Ando, and M. Sharon, "Growth of vertically aligned carbon nanotubes on silicon and quartz substrate by spray pyrolysis of a natural precursor: turpentine oil," Chemical Physics Letters, vol. 414, no. 1-3, pp. 6-10, 2005.

[7] L. F. Su, J. N. Wang, F. Yu, Z. M. Sheng, H. Chang, and C. Pak, "Continuous production of single-wall carbon nanotubes by spray pyrolysis of alcohol with dissolved ferrocene," Chemical Physics Letters, vol. 420, no. 4-6, pp. 421-425, 2006.

[8] G. Nabiyouni, "Giant magnetoresistance in spintronic $\mathrm{Co} / \mathrm{Pt}$ nanowire structures," Metrology and Measurement Systems, vol. 15, no. 2, pp. 135-143, 2008.

[9] V. A. Antohe, A. Radu, S. Yunus, et al., "A versatile method to grow localized arrays of nanowires for highly sensitive capacitive devices," Journal of Optoelectronics and Advanced Materials, vol. 10, no. 11, pp. 2936-2941, 2008.

[10] N. D. Hoa, N. Van Quy, M. An, et al., "Tin-oxide nanotubes for gas sensor application fabricated using SWNTs as a template," Journal of Nanoscience and Nanotechnology, vol. 8, no. 10, pp. 5586-5589, 2008.

[11] J. Y. Park, J.-J. Kim, and S. S. Kim, "Ambient air effects on electrical transport properties of $\mathrm{ZnO}$ nanorod transistors," Journal of Nanoscience and Nanotechnology, vol. 8, no. 11, pp. 5929-5933, 2008.

[12] J. B. Baxter and E. S. Aydil, "Metallorganic chemical vapor deposition of $\mathrm{ZnO}$ nanowires from zinc acetylacetonate and oxygen," Journal of the Electrochemical Society, vol. 156, no. 1, pp. H52-H58, 2009.

[13] B. He, T. J. Morrow, and C. D. Keating, "Nanowire sensors for multiplexed detection of biomolecules," Current Opinion in Chemical Biology, vol. 12, no. 5, pp. 522-528, 2008.

[14] G. Neri, G. Micali, A. Bonavita, et al., "Tungsten oxide nanowires-based ammonia gas sensors," Sensor Letters, vol. 6, no. 4, pp. 590-595, 2008.

[15] S. Lettieri, A. Setaro, A. Bismuto, et al., "Light emission properties of $\mathrm{SnO}_{2}$ nanowires for applications in gas sensing," Sensor Letters, vol. 6, no. 4, pp. 596-600, 2008. 
[16] J. Martinez, R. V. Martínez, and R. Garcia, "Silicon nanowire transistors with a channel width of $4 \mathrm{~nm}$ fabricated by atomic force microscope nanolithography," Nano Letters, vol. 8, no. 11, pp. 3636-3639, 2008.

[17] J.-W. Lee, K.-J. Moon, M.-H. Ham, and J.-M. Myoung, "Dielectrophoretic assembly of GaN nanowires for UV sensor applications," Solid State Communications, vol. 148, no. 5-6, pp. 194-198, 2008.

[18] M. S. Mohlala, X.-Y. Liu, J. M. Robinson, and N. J. Coville, "Organometallic precursors for use as catalysts in carbon nanotube synthesis," Organometallics, vol. 24, no. 5, pp. 972976, 2005.

[19] O. N. Srivastava, A. Srivastava, D. Dash, et al., "Synthesis, characterizations and applications of some nanomaterials $\left(\mathrm{TiO}_{2}\right.$ and $\mathrm{SiC}$ nanostructured films, organized CNT structures, $\mathrm{ZnO}$ structures and CNT-blood platelet clusters)," Pramana, vol. 65, no. 4, pp. 581-592, 2005.

[20] F. Paraguay-Delgado, W. Antúnez-Flores, M. Miki-Yoshida, et al., "Structural analysis and growing mechanisms for long $\mathrm{SnO}_{2}$ nanorods synthesized by spray pyrolysis," Nanotechnology, vol. 16, no. 6, pp. 688-694, 2005.

[21] K. C. Pingali, D. A. Rockstraw, and S. Deng, "Silver nanoparticles from ultrasonic spray pyrolysis of aqueous silver nitrate," Aerosol Science and Technology, vol. 39, no. 10, pp. 1010-1014, 2005.

[22] K. C. Pingali, D. A. Rockstraw, and S. Deng, "Synthesis of carbon nanoparticle thin film with spray pyrolysis," New Mexico Journal of Science, vol. 44, pp. 149-163, 2006.

[23] T. Doi, A. Fukuda, Y. Iriyama, et al., "Low-temperature synthesis of graphitized nanofibers for reversible lithium-ion insertion/extraction," Electrochemistry Communications, vol. 7, no. 1, pp. 10-13, 2005.

[24] K. C. Pingali, S. Deng, and D. A. Rockstraw, "Deposition of Ru-Ni-S nanoparticles on carbon by spray-pyrolysis: effects of solvent and other processing parameters," Current Nanoscience, vol. 3, no. 3, pp. 215-221, 2007.

[25] R. L. Vander Wal and T. M. Ticich, "Comparative flame and furnace synthesis of single-walled carbon nanotubes," Chemical Physics Letters, vol. 336, no. 1-2, pp. 24-32, 2001. 

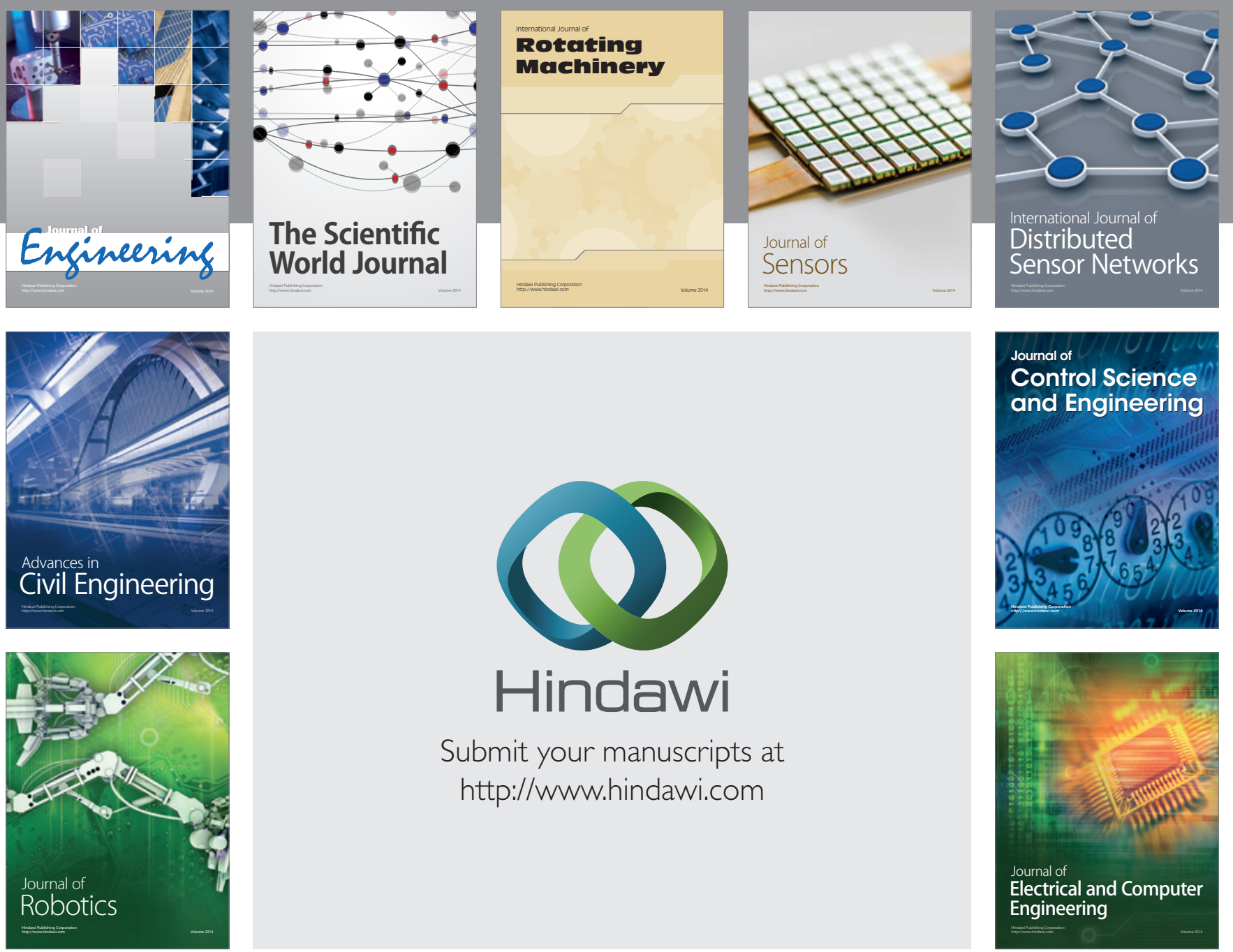

Submit your manuscripts at

http://www.hindawi.com
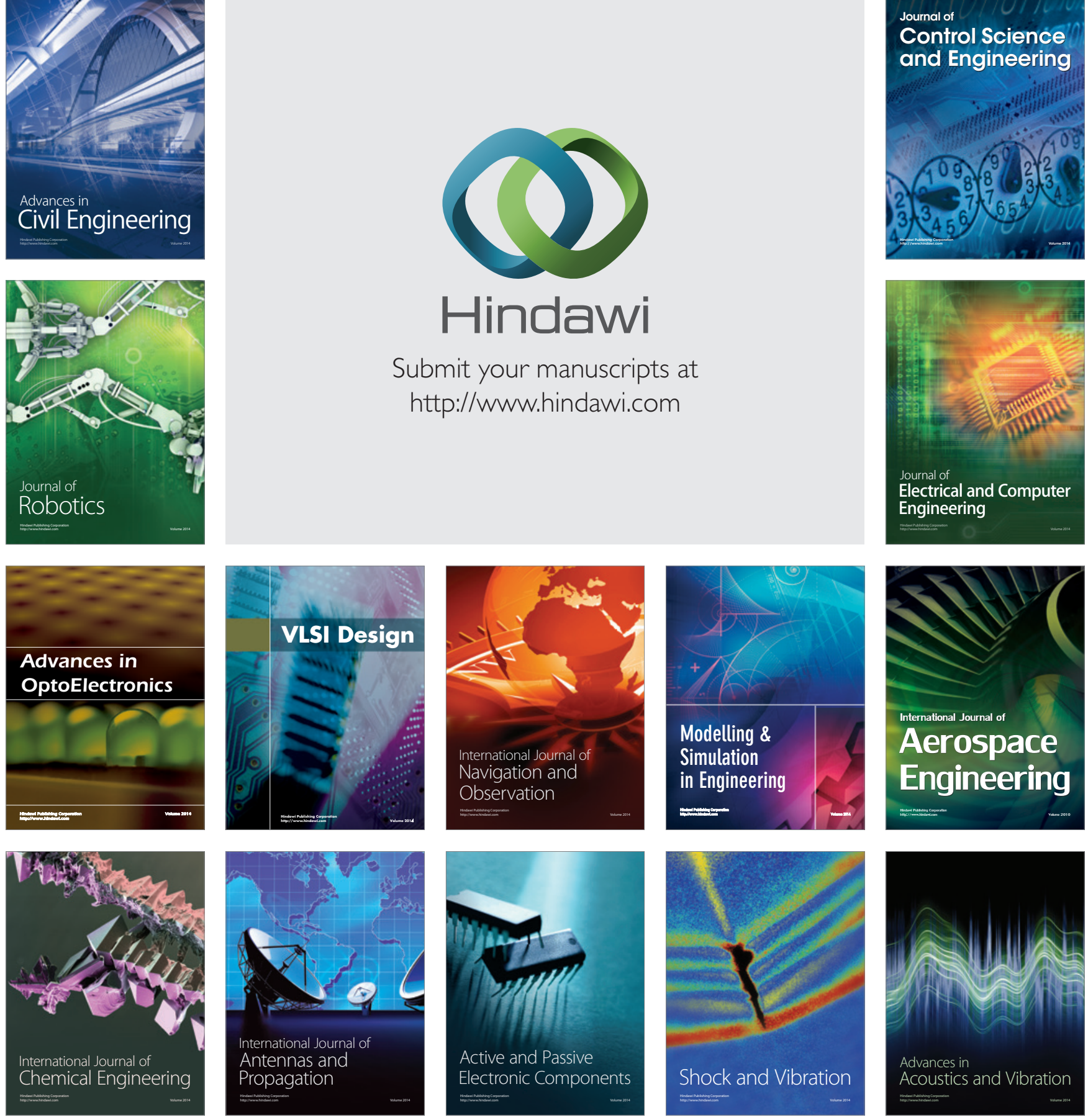